\title{
Evaluating Methods for Counting Aircraft Operations at
}

Non-Towered Airports

Project funded by the Transportation Research Board's Airport Cooperative Research Program Project ACRP 03-27

Maria J. Muia, Ph.D. Principal Investigator Woolpert, Inc.

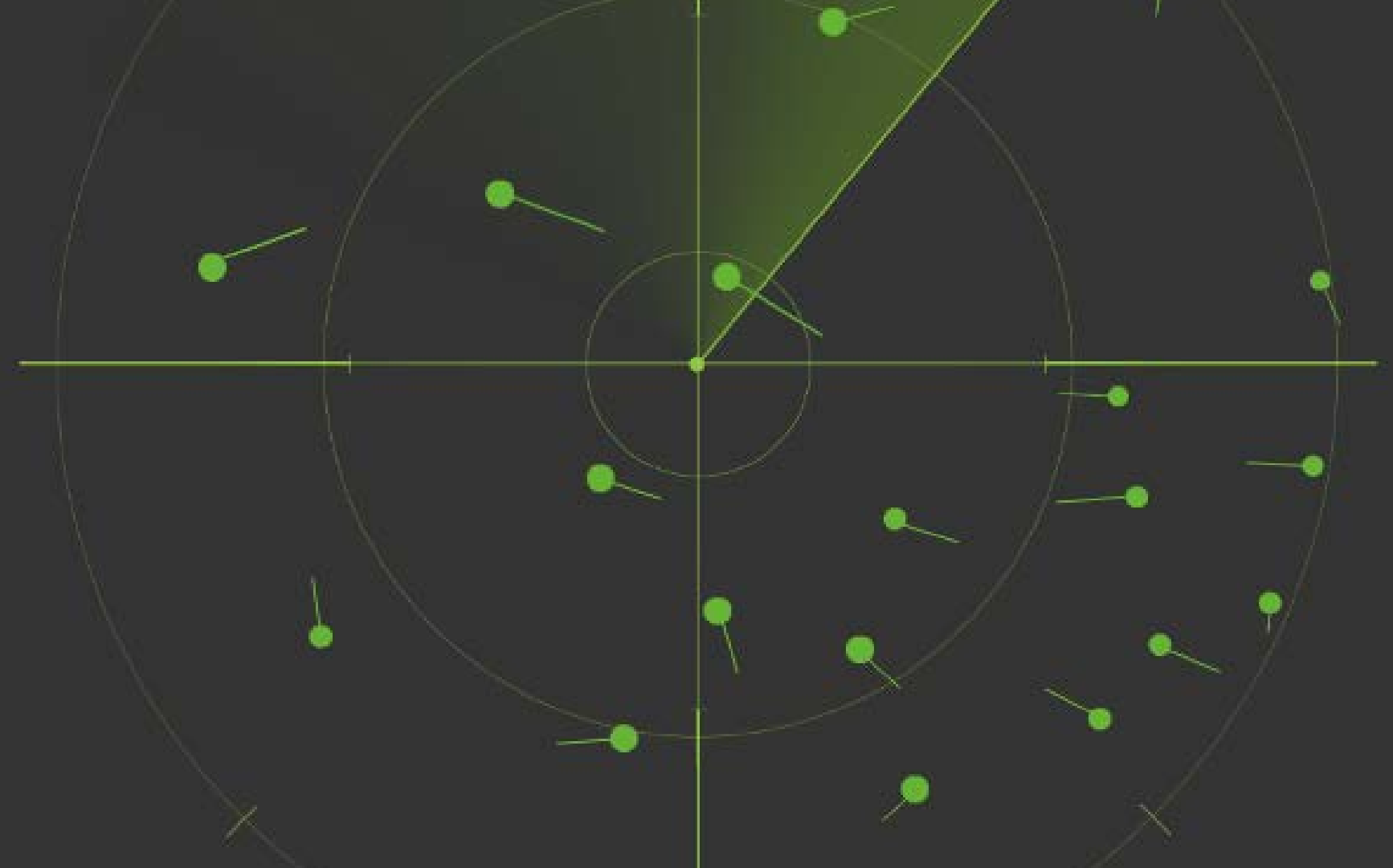

Mary Johnson, Ph.D. Aviation Technology Associate Professor Purdue University 


\section{Does Anyone Care about Airport}

Operations Estimates?

- Airports, States, FAA

- Why?
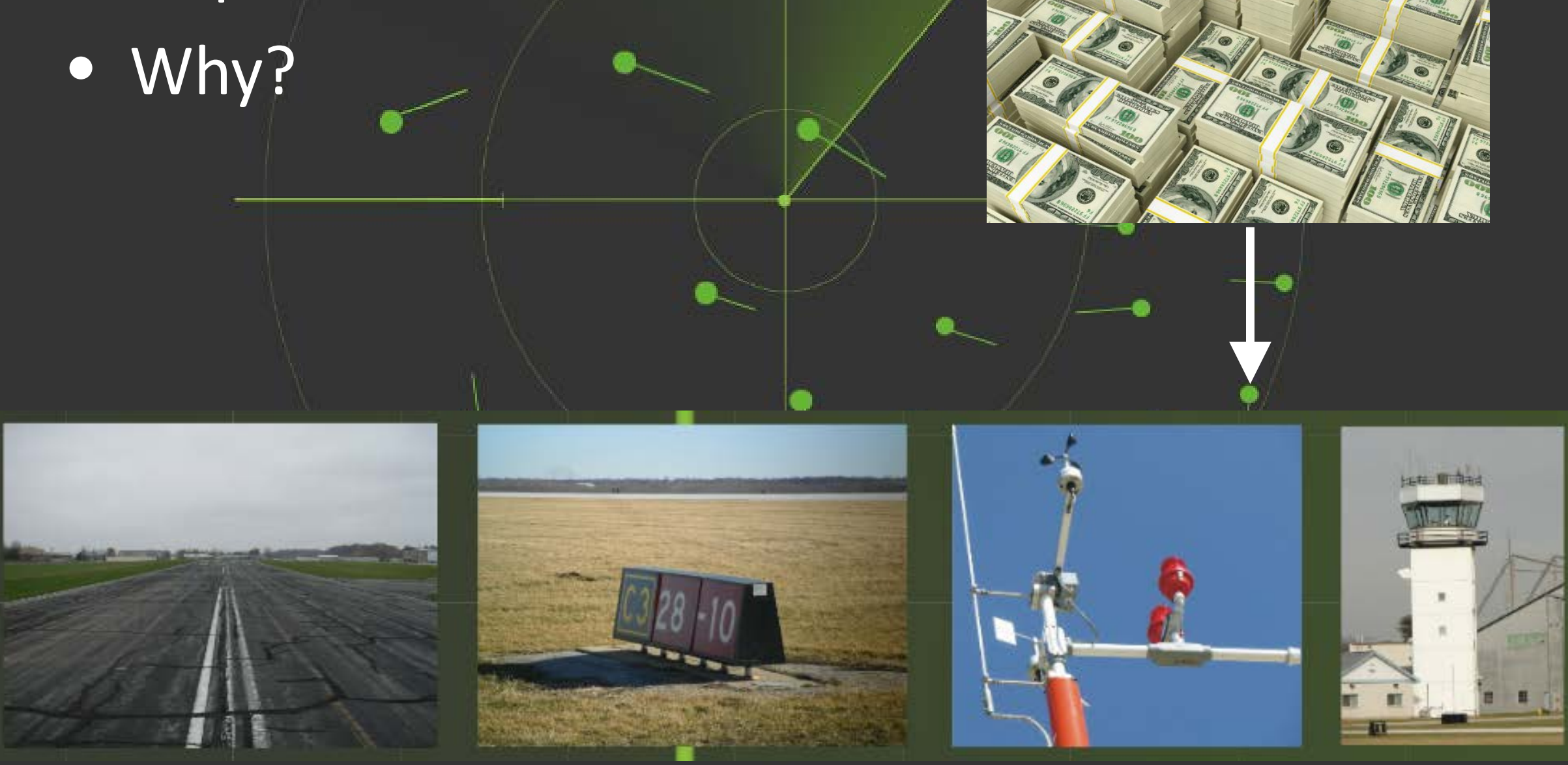


\section{Fun Facts}

- Approximately 3300 public airports in FAA system plan

- Only about 500 public airports have an air traffic control tower that tracks airport takeoffs and landings (operations)

- How much traffic occurs at those airports without towers?

\section{INDIANA}

\& 115 Public Airports

\& 12 with ATC Towers

\& 3037 based single engine GA aircraft $*>1.2 \mathrm{M}$ GA operations each year 


\section{We Reviewed, 3 Estimating Methods}

1 - Multiplying the number of based aircraft by an estimated number of operations per based aircraft (OPBA)

2 - Applying a ratio of FAAinstrument flight plans to total operations (IFPTO)

3 - Expanding a sample count into an annual estimate through statistical extrapolation.

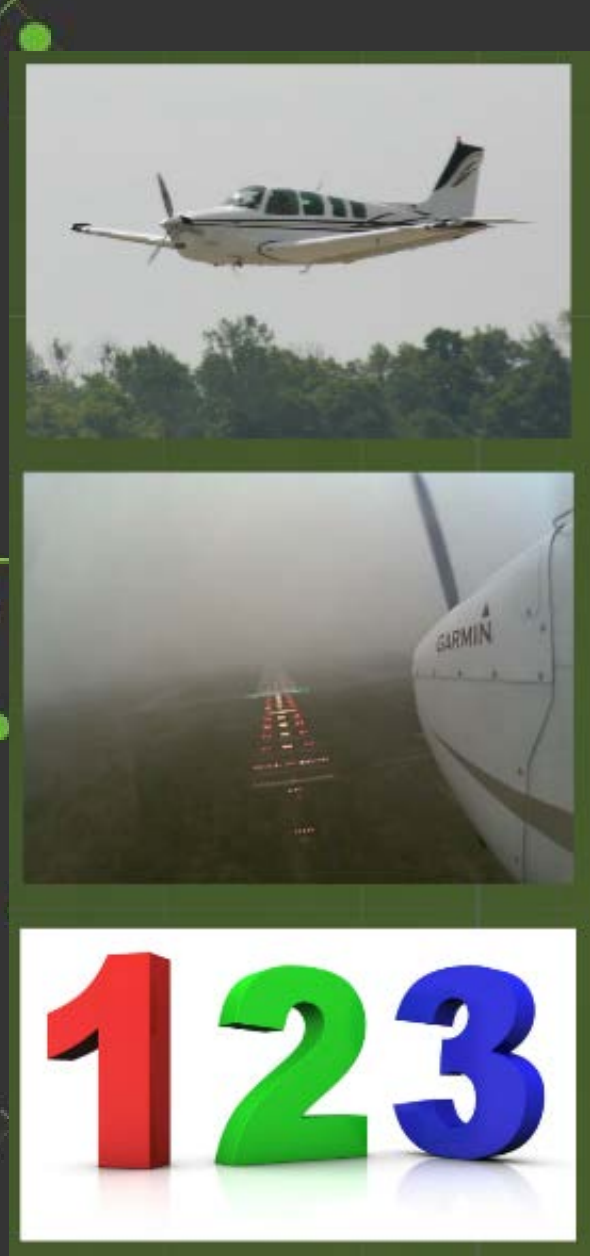




\section{OPBA}

- Is there a consistent number(s) of OPBA that occur at small, towered airports that can then be applied to non-towered airports? (taking into account climate, population, and flight schools)

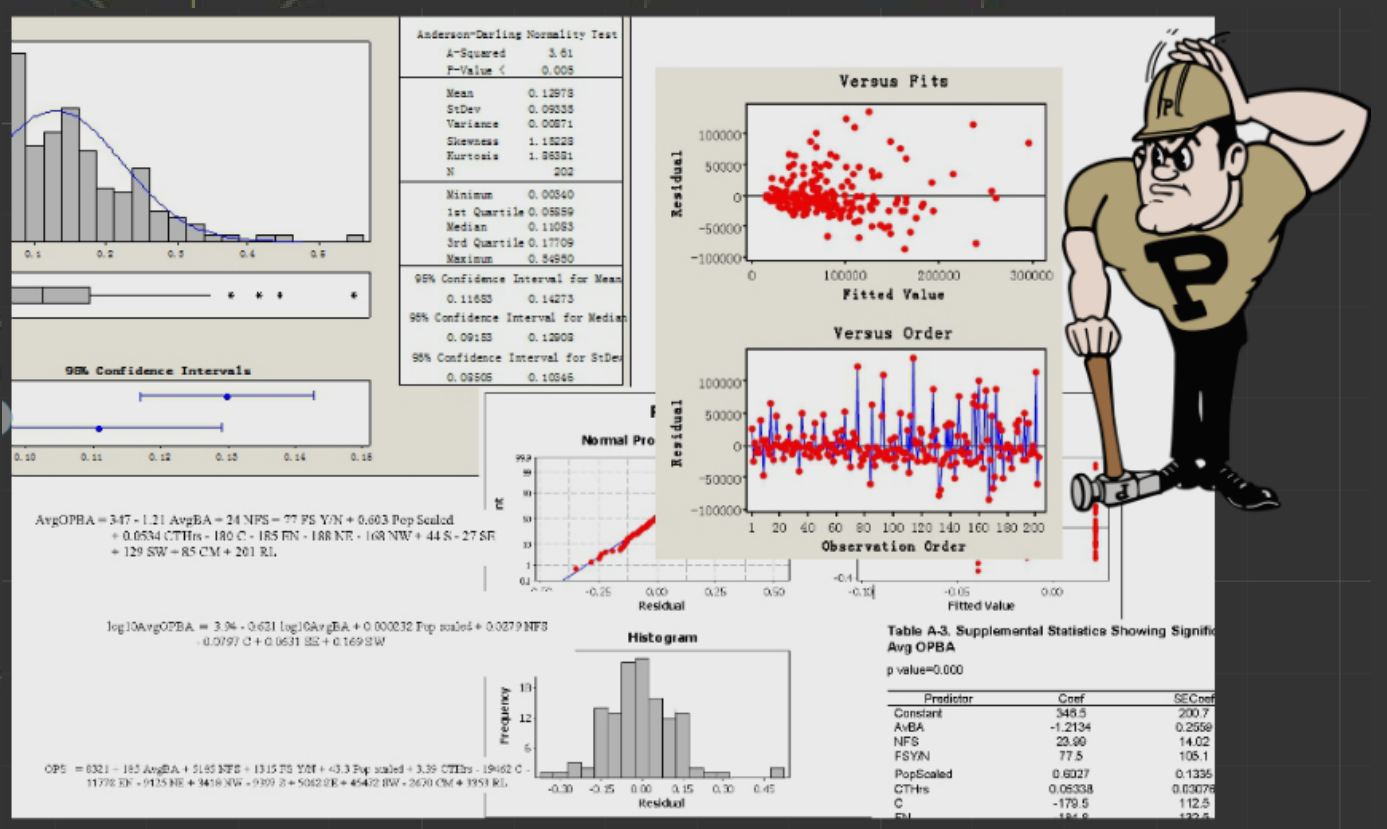




\section{Summary of OPBA by Region}

Table A-2 Summary of Small Towered Airport Data by Region Used in this Study

\begin{tabular}{|c|c|c|c|c|c|c|c|c|c|}
\hline \multirow{3}{*}{$\begin{array}{l}\text { NOAA } \\
\text { Climate } \\
\text { region } \\
\text { Alaska }\end{array}$} & \multirow{3}{*}{$\begin{array}{c}\text { Number } \\
\text { of } \\
\text { airports }\end{array}$} & \multirow{3}{*}{$\begin{array}{c}\text { AvgBA } \\
\text { per } \\
\text { region }\end{array}$} & \multirow{3}{*}{$\begin{array}{c}\text { Avg } \\
\text { Ops per } \\
\text { region }\end{array}$} & \multirow{3}{*}{$\begin{array}{l}\text { AvgPop } \\
283,382\end{array}$} & \multirow{3}{*}{$\begin{array}{l}\text { OPBA } \\
\text { mean } \\
157.40\end{array}$} & \multirow{3}{*}{$\begin{array}{l}\text { median } \\
157.40\end{array}$} & \multirow{2}{*}{$\begin{array}{l}\text { OPBA } \\
95 \% \text { Confidence } \\
\text { Interval for the } \\
\text { median }\end{array}$} & \multicolumn{2}{|c|}{ OPBA range } \\
\hline & & & & & & & & Low & High \\
\hline & & & & & & & NA & NA & NA \\
\hline Central & 33 & 141.01 & 49,187 & 162,441 & 429.54 & 360.13 & $(298.02,426.85)$ & 201.75 & $1,015.54$ \\
\hline E. N. Central & 13 & 188.52 & 67,823 & 260,933 & 473.92 & 462.29 & $(266.65,550.52)$ & 177.42 & 798.85 \\
\hline Hawaii & 1 & 22.80 & 104,224 & 13,689 & $4,771.68$ & 4771.6 & NA & NA & NA \\
\hline Northeast & 28 & 187.06 & 72,081 & 353,687 & 432.95 & 408.37 & $(351.95,504.20)$ & 225.91 & 828.52 \\
\hline Northwest & 8 & 202.90 & 80,577 & 224,704 & 382.95 & 779.38 & $(264.80,453.03)$ & 219.87 & 779.38 \\
\hline South & 41 & 154.19 & 65,312 & 352,947 & 597.89 & 338.00 & $(302.52,522.53)$ & 132.17 & $2,481.89$ \\
\hline Southeast & 38 & 212.66 & 95,457 & 171,804 & 561.74 & 439.42 & $(338.62,572.66)$ & 190.89 & $2,491.54$ \\
\hline Southwest & 15 & 394.01 & 16,802 & 391,318 & 487.23 & 396.66 & $(336.31,646.39)$ & 192.52 & 819.86 \\
\hline West & 27 & 381.98 & 124,391 & 388,546 & 370.13 & 326.30 & $(282.28,362.85)$ & 139.69 & 875.89 \\
\hline W.N. Central & 0 & NA & NA & NA & NA & NA & NA & NA & NA \\
\hline Overall & 205 & 222.35 & 85,890 & 394,118 & 501.68 & 377.78 & $(350.30,412.86)$ & 132.17 & $4,471.68$ \\
\hline
\end{tabular}

Legend:

Avg $=$ Average

$\mathrm{BA}=$ Based Aircraft

Ops = Operations

OPBA = Operations per Based Aircraft

NA $=$ Not Applicable

Prepared by: Purdue University 


\section{Based on the study objectives and data -}

- There were no practical and consistent OPBAs found or modeled at small, towered airports nationally or by climate region, even when considering the number of flight schools based at the airport.

- Therefore, the research team cannot recommend an OPBA or OPBA equation for estimating annual operations at non-towered airports. 


\section{IFPTO}

- Is there a consistent ratio of IFR flight plans to total operations (IFPTO)

that can be used to estimate operations at non-towered airports? (taking into account climate)

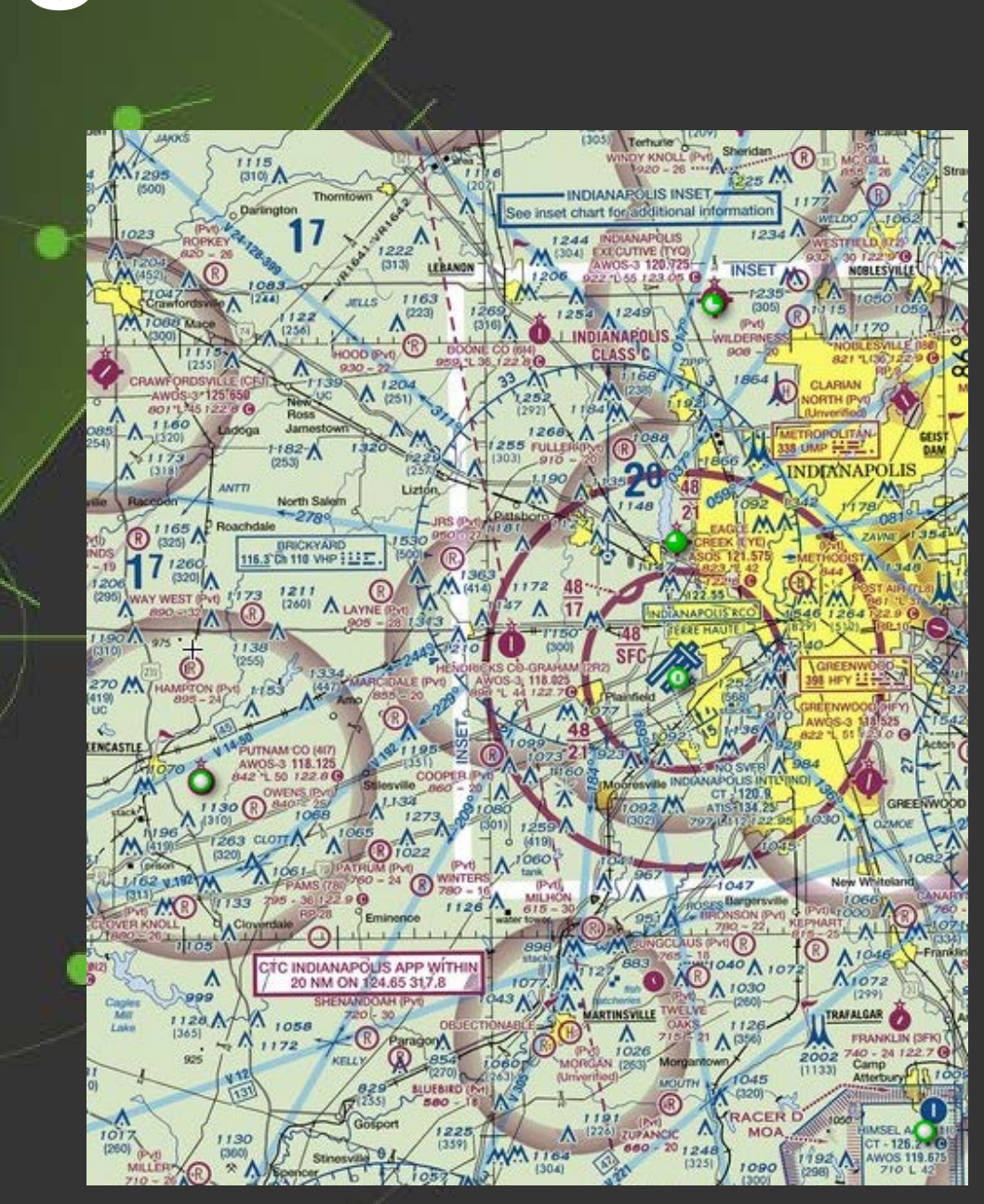

Sectional screenshot from www.SkyVector.com 


\section{Based on the study objectives and data -}

- No practical and consistent IFPTOs found in the dataset of small towered airports nationally or by climate region.

- Cannot recommend an IFPTO for estimating annual operations at non-towered airports.

- Recommendation: take sample of actual operations and extrapolating into annual operations from the sample. 


\section{Statistical Extrapolation}

Tested sample sizes and time frames of

A. One week in each season

B. Two weeks in each-season

C. One month in spring, summer, or fall

D. One month in winter 
Table 3A-9: Summary of the Percent Difference Between Estimates Using Monthly/Seasonal Factors and OPSNET Annual Operations

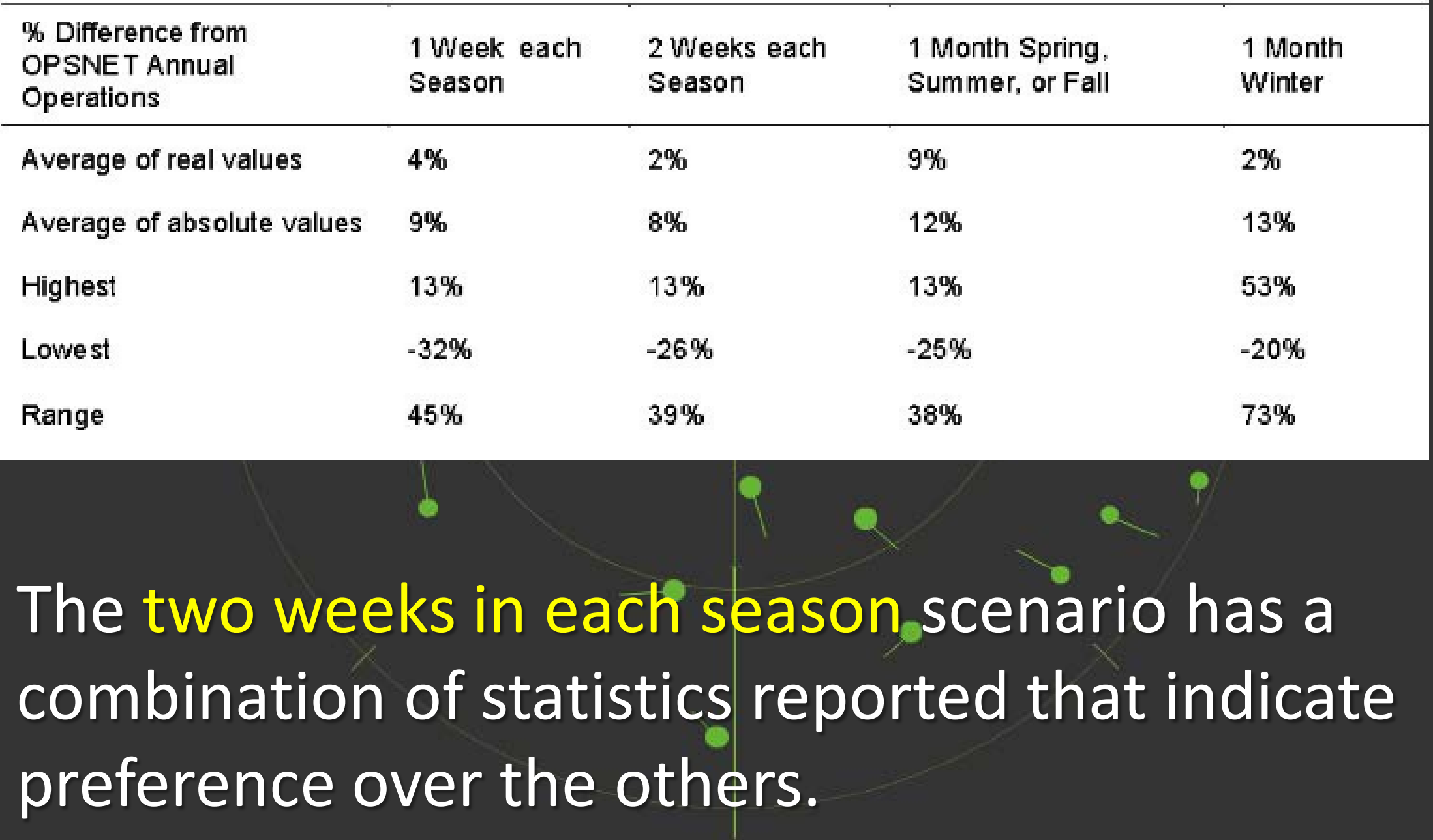




\section{How to take samples?}

Aircraft Traffic Counters

Different aircraft counting technologies included

1 - automated acoustical counter.

2 - sound-level meter acoustical counter,

3 - security/trail cameras, and

4 - video image detection with a transponder receiver.

Tested at TYQ, 142, EYE, and LAF 


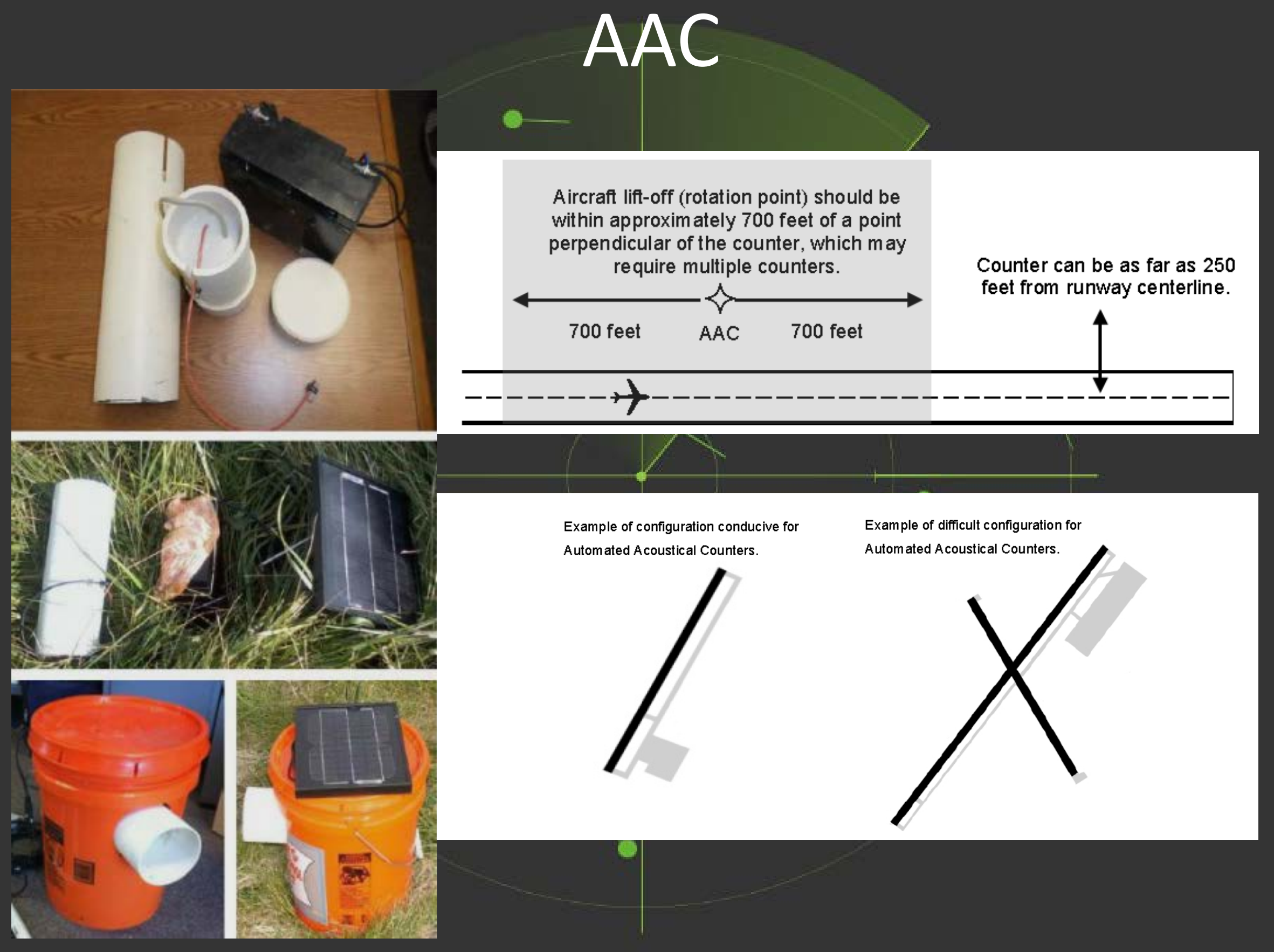




\section{SMAC}
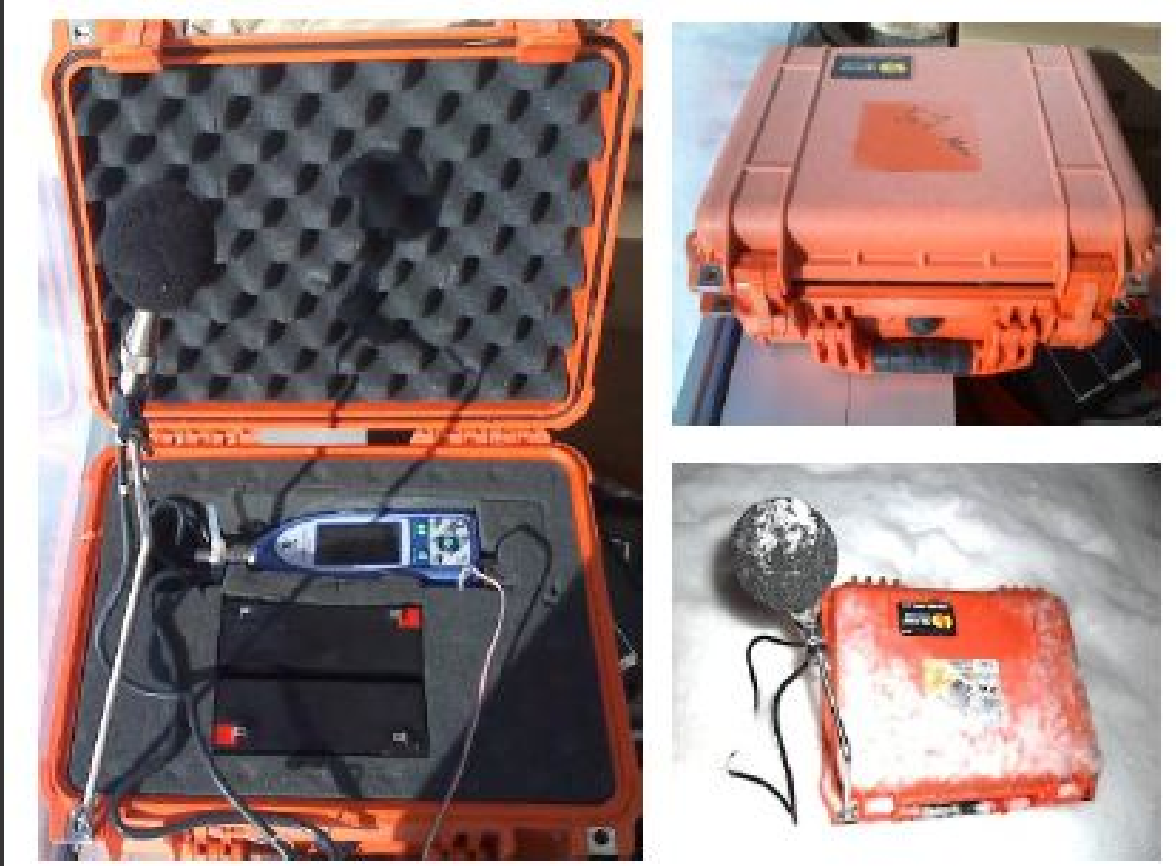

Exam ple of configuration conducive for

Sound-Level Meter Acoustical Counters.

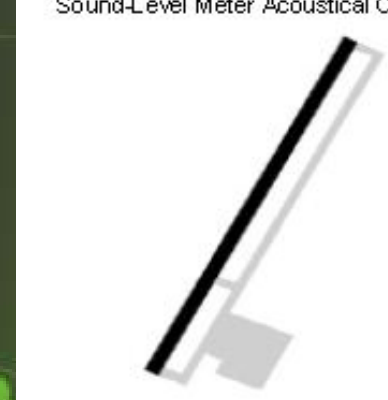

Example of difficult configuration for Sound-

Level Meter Acoustical Counters.
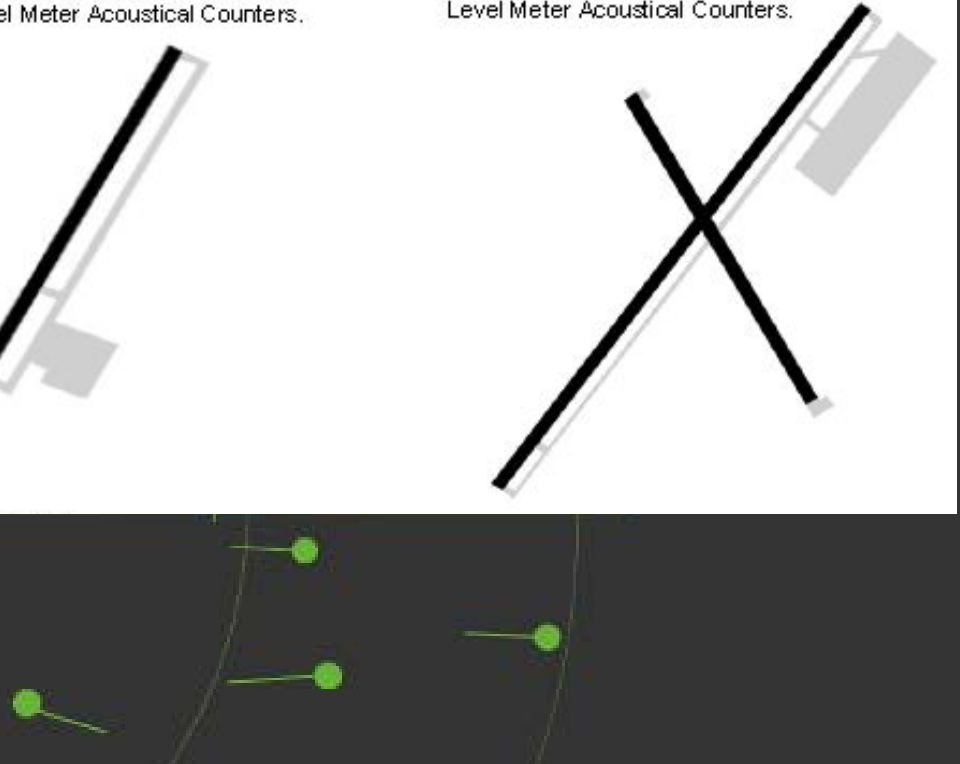

Ajrcraft lift-off (rotation point) should be within approxim ately 700 feet of a point perpendicular of the counter, which may require multiple counters.

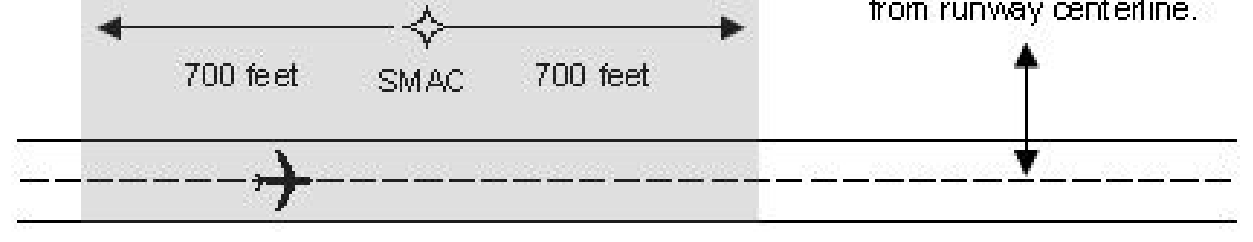

Counter can be as far as 75 feet from runmay centerline. 
VID
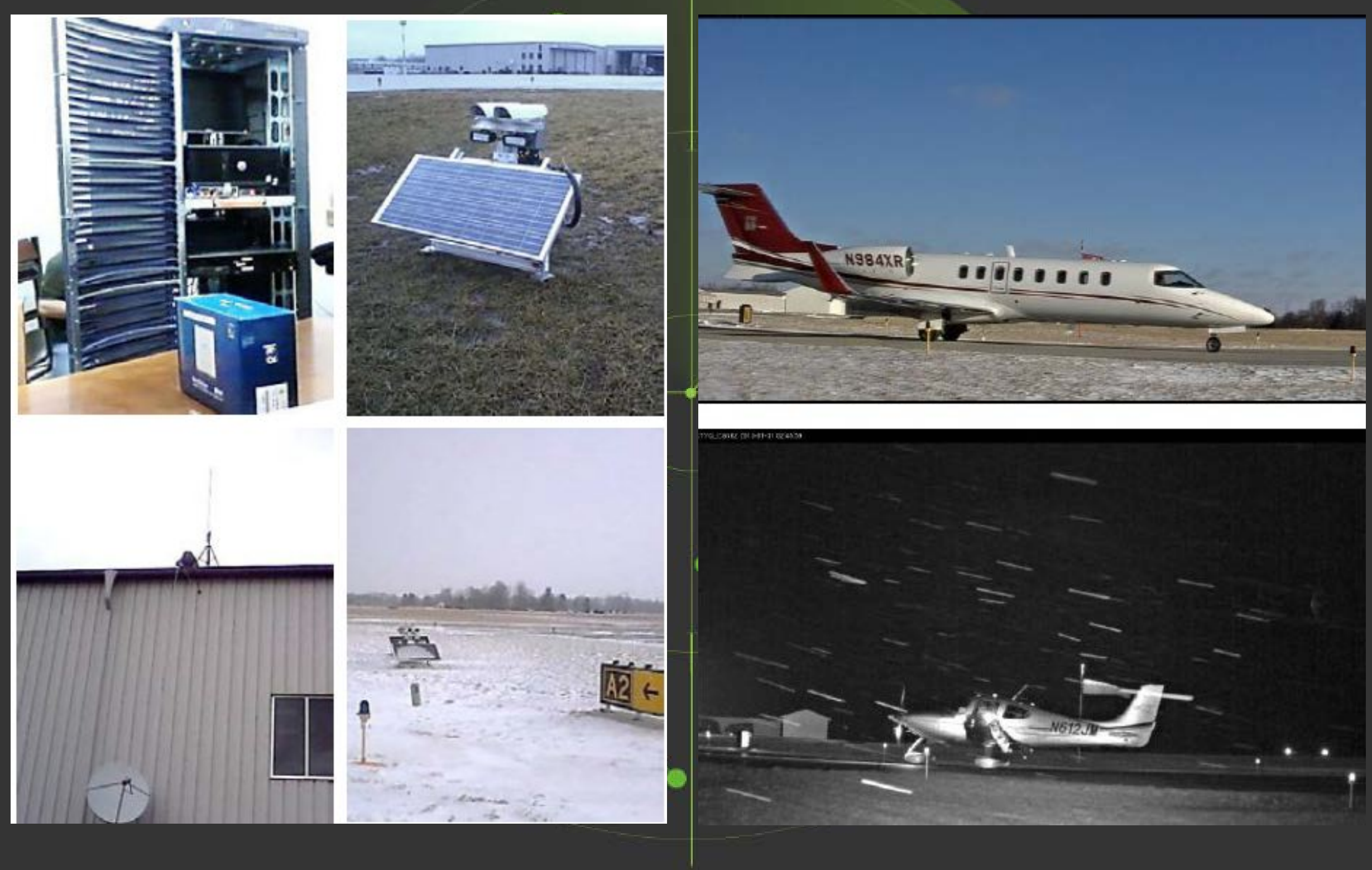


\section{Video Image Detection and ADS-B Transponder Receiver Highlights}

Best used at arports whit centralized terminal and hangar area with limited access points and litte touch-and-go activity.

- Accuracy levels as high as $90 \%$ were achieved for recording aircraft entering or exiting the rurway environment.

- Unable to count touch-and-goes.

- ADS-B transponder receiver option adds little to no value considering the low equipage rate of the U.S. general aviation fleet with ADS-B out.

- Most expensive option.

- Least labor intensive option.

- Requires service contract.

- Can also be used for automated billing of landing fees.

Example of configuration conducive for Video In age Detection.

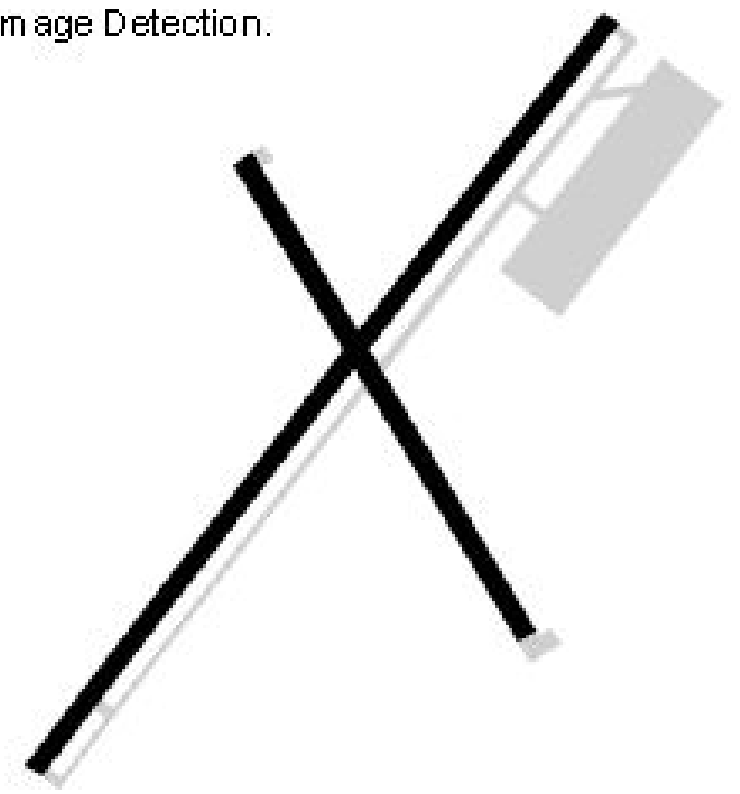

Example of difficult configuration for Video Im age Detection. 


\section{S/TC}
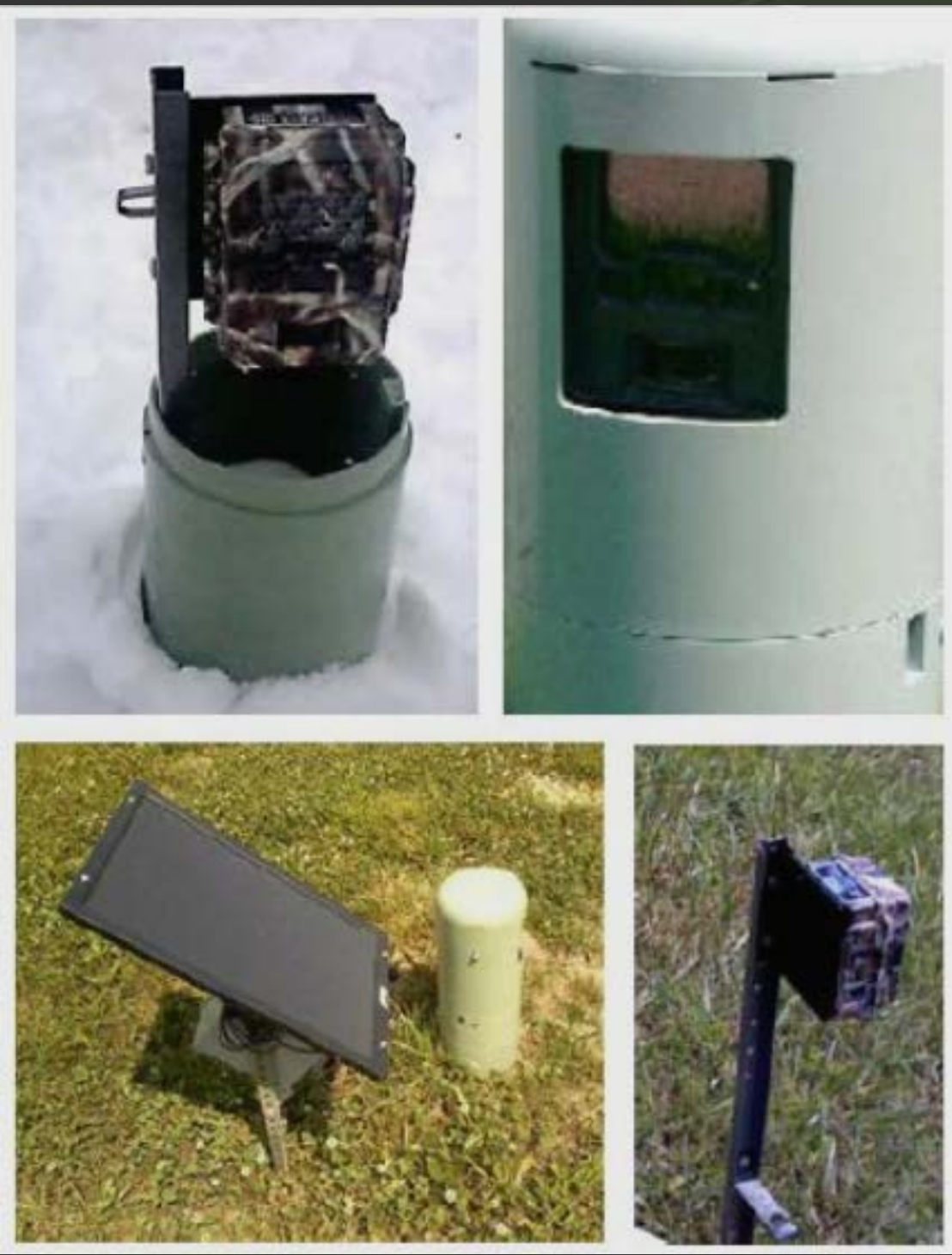

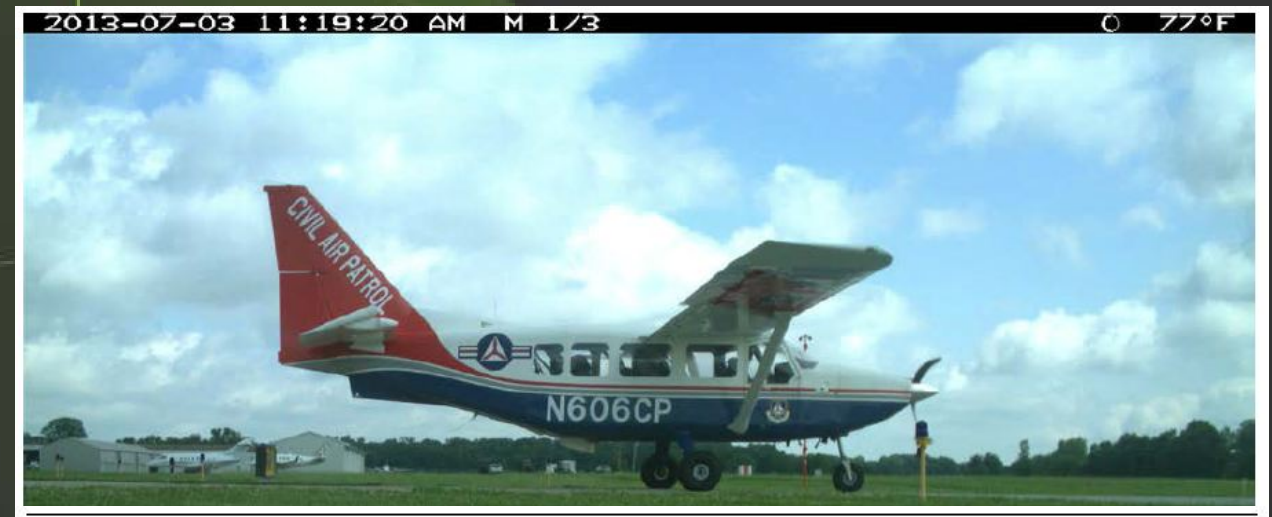

Security/Trail Camera Highlights

Best used at arports whin centralized terminal and hangar area with limited access points and litte touch-and-go activity.

- Accuracy levels approaching $100 \%$ can be achieved for recording aircraft entering or exiting the runway environment.

- Unable to count touch-and-goes.

- Exceptionally slow moving aircraft may be missed

- As ambient temperature approaches temperature of target aircraft, target may be missed.

- Labor intensive bec ause manual tally of images is required.

- Information on aircraft type, make, and model can be obtained from aircraft registration number.

- Low cost for airports with simple airfield configurations

- Can also be used for detecting wildlife.

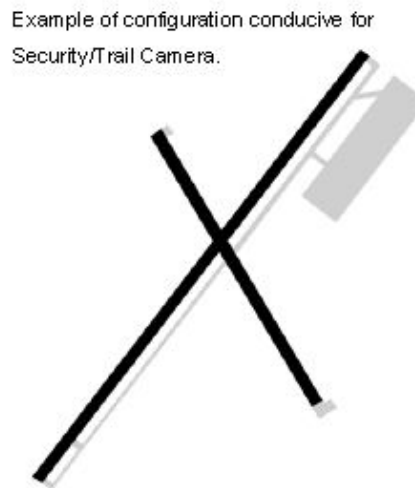

Example of difficult configuration to Security/T rail Camera.

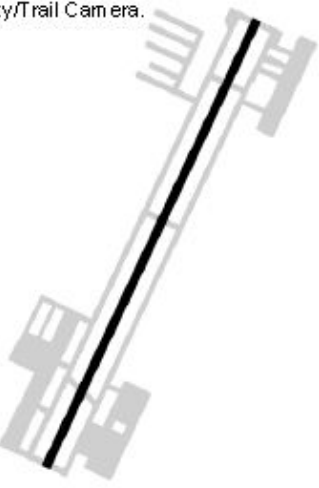


Not all images are planes

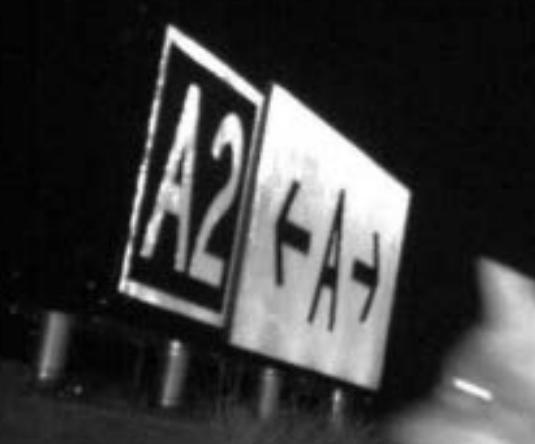


Not all birds are planes 


\section{Wildlife and planes don't mix}

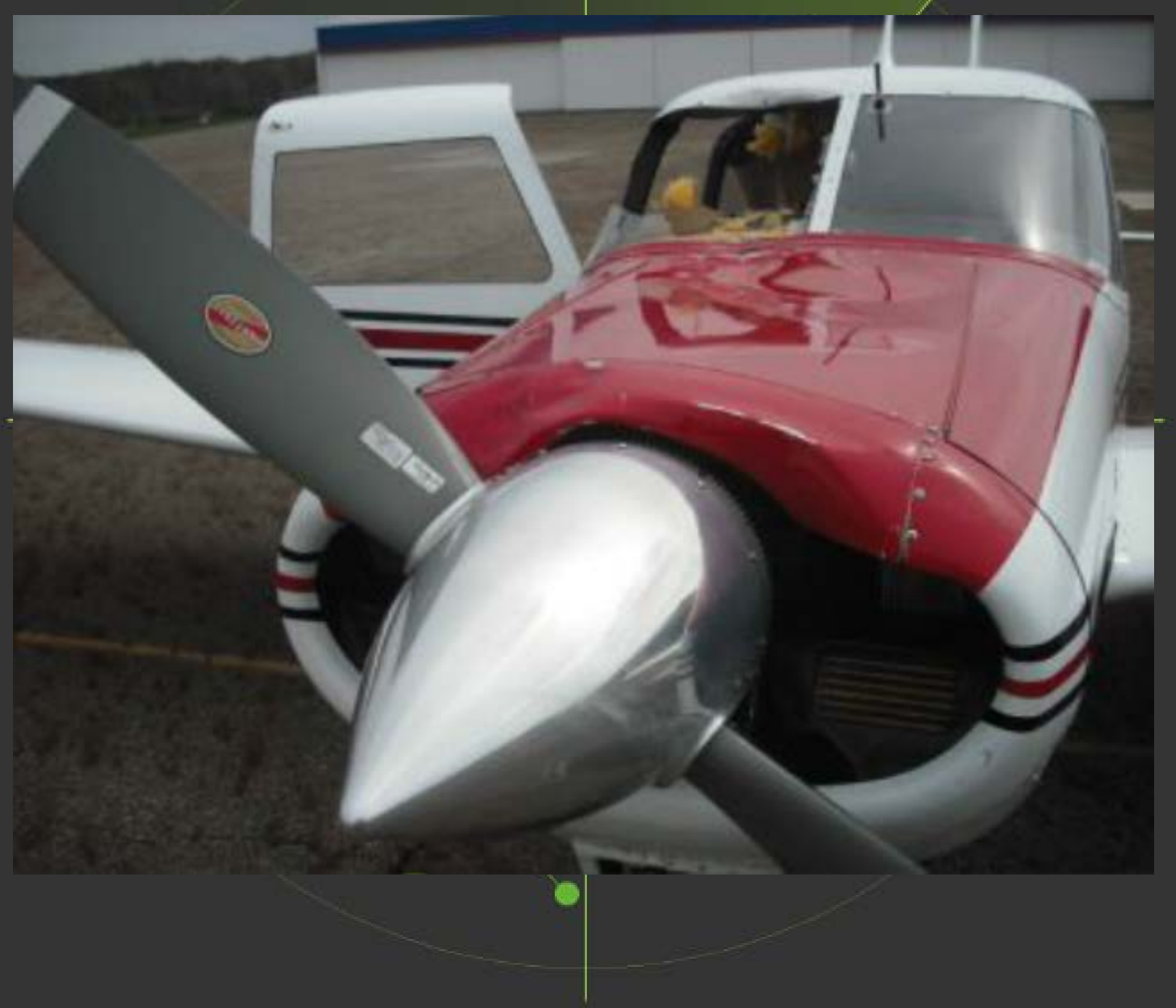


General Aviation

Nonstop Service to Everywhere! 